\title{
INFECTIC
}
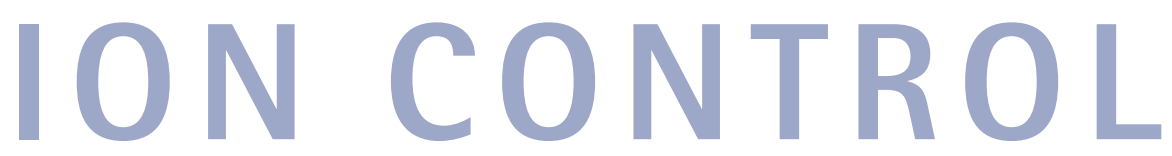

\section{A new agreement}

A new agreement between the Dental Directory and the Zirc company means that Zirc's range of specialist products is available to dentists within the UK.

Most of Zirc's plastic products can be autoclaved, chemiclaved and surface disinfected repeatedly and features designed to protect both the patient and surgery staff.

Also available is the Total colour code system. The Dental Directory claims this system helps staff organise their practice, allowing them to manage instruments and materials with less stress and confusion, improving their productivity and efficiency.

For more information phone 0800585586. Reader response number 56

\section{Prestige are clean}

Prestige Dental offers a wide range of dental products, including a range in infection control. One of these, a disiefectant, is the Micro $10+$.

Also included in Prestige Dental's range is the Uniclean Spray - active foam for simultaneous disinfection, cleaning and maintenance for even the most delicate surfaces and Dermocol - a broad-spectrum, alcohol-based antiseptic that allows you to hygienically disinfect your hands by simply rubbing it on like hand cream For further details phone 0800591175. Reader response number 57

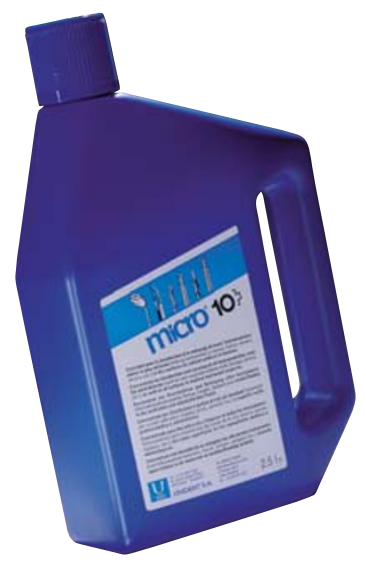

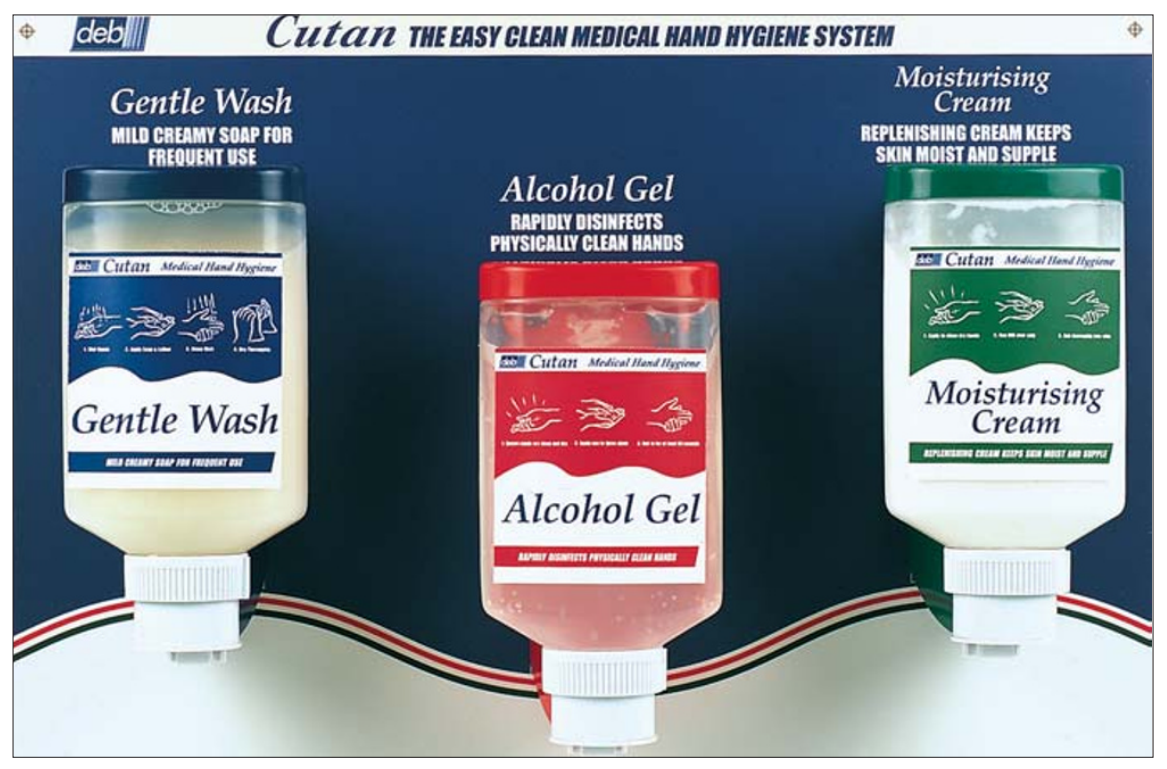

\section{A wall mounted, triple action hygiene system}

Deb Ltd, one of the UK's leading supplier of hand hygiene products for hospitals, are now extending their successful Cutan range to include a unique new 3-Step Hand Hygiene System.

The Cutan Hand Hygiene System has been specifically designed for low traffic healthcare environments, including doctor's surgeries, medical centres, residential homes, dentists, veterinary practices and opticians.

Deb Ltd claims the new system is easy-to-use, hygienic, extremely cost effective and includes everything required for an effective hand hygiene and hand care programme. The set comes complete with three $300 \mathrm{ml}$ dispensers (including cartridges) fixed on a wall mountable board, and all the fittings required for a simple, easy installation. It will fit neatly on any flat wall surface, keeping products off-the-sink, even where space is limited. For more information phone 01773880367.

Reader response number 55

\section{Would you like to tell the time in any weather}

Alkapharm are offering a free weather station wall clock to everyone ordering Alkazyme throughout October. Alkazyme Enzymatic is used for instrument decontamination and Alkapharm claim it is popular with dental practices.

Alkapharm also claims Alkazyme is easy to use and economical, and can be used in either immersion or ultrasonic bath (available as an optional extra). Alkazyme is available in a 750 gram economy tub with a dosing spoon, which makes 150 litres of useable solution, or a tub of 100 water soluble sachets, with each sachet making 1 litre of solution.

For more information phone 01785714919.

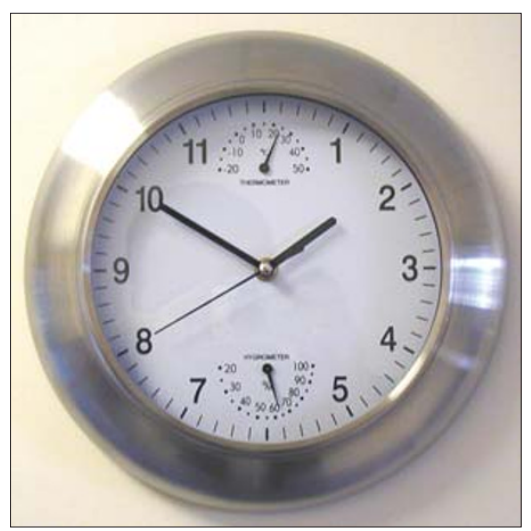
Reader response number 58 


\section{The Vacuklav 31-B from Minverva}

In Minerva's range of autoclaves is the Vacuklav 31-B table top autoclave. Minerva claims the Vacuklav conforms to EU and UK Regulations. Fully automatic, it is easy to operate at the simple touch of a button and conforms to HTM 2010 the NHS Standard for bench top autoclaves.

One of the features is a large 17 litre chamber, which can hold up to 6 instrument trays. It has a 9 minute fast cycle for when sterile instruments are needed in a hurry.

Minverva claims the Vacuklav 31-B is simple to install because it requires no water connection. Moreover, unlike many other makes, which reuse condensed dirty water, it uses fresh, clean, demineralised water every cycle.

For more information phone 02920 490504.

Reader response number 59

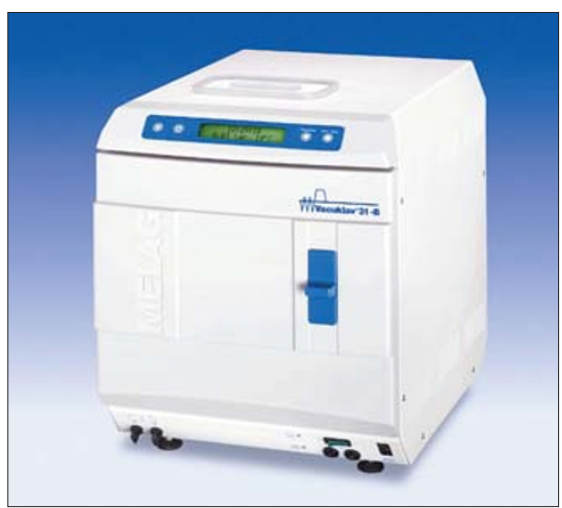

\section{Disposable air and water syringe tips}

The Sani-Tip from Dentsply is part of the their range of infection control products. The Sani-Tip features a central water channel encircled by six separate air channels, which when combined with appropriate adaptor, produces precise atomisation of air and water.

Dentsply claims that besides preventing cross-contamination, a disposable air/water

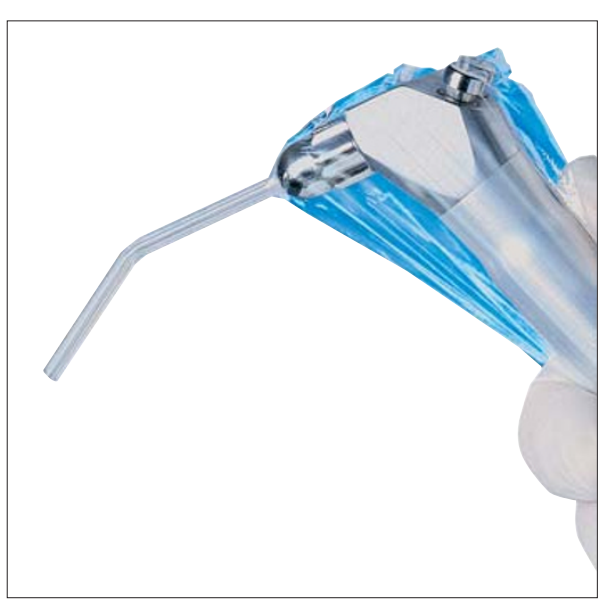
syringe tip saves time and money by decreasing time for operatory turnover. The clear plastic does not obstruct the field of operation and allows members to determine whether the tip has been previously used.

Also available to the Sani-Tip system is the patented tapered water spindle inside each adaptor. Dentsply also claims when a Sani-Tip is fully seated over the spindle, a self-sealing water channel is created guaranteeing dry air under optimal pressure.

For more information or a demonstration in your surgery phone Dentsply on 01932 837205.

Reader response number 60

\section{Septodont offer you total protection}

Septoguard is the name given to the range of infection control products from Septodont. The range is dedicated to provide the best in dental hygiene and Septodont claims it offers specific cross infection products to clean and disinfect all areas, from aspirators and instruments to hard surfaces within a practice.

In the Septoguard range is Bioseptol. The Bioseptol is a new generation of disinfectant specially designed for use on stainless steel, plastic, glass and Wironit instruments only. Septodont claims that Bioseptol is formulated from peracetic acid, a powerful disinfecting agent that shortens the required contact time of the instruments with the solution.

For more information phone 0800435155 or visit www.septodont.co.uk.

Reader response number 61

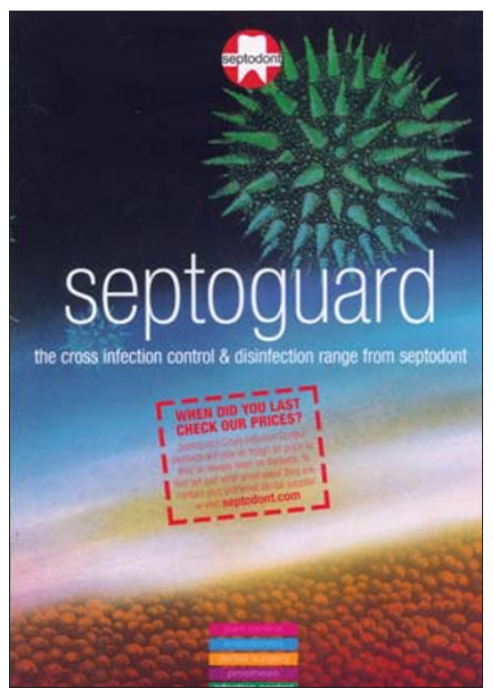

